\title{
ВЛИЯНИЕ АНТРОПОГЕННОГО ЗАГРЯЗНЕНИЯ НА СОСТАВ ОРНИТОФАУНЫ ПАРКОВ ГОРОДА МОСКВЫ
}

\section{INFLUENCE OF ANTHROPOGENIC POLLUTION ON THE COMPOSITION OF AVIFAUNA IN MOSCOW PARKS}

E. Makarova

V. Ostapenko

Summary. Anthropogenic transformation of the environment, including urban parks, has a significant impact on almost all groups of vertebrates, including birds. The paper analyzes the impact of anthropogenic pollution on the diversity of birds in forest parks on the example of the city of Moscow. The dependences of reducing the species diversity of birds with a high level of transformation of the biocenosis are revealed.

Keywords: species diversity, birds, noise pollution, light pollution, transformed biocenoses, route accounting.

\author{
Макарова Елена Александровна \\ К.б.н., доцент, Московская государственная \\ академия ветеринарной медицины и биотехнологии \\ имени им. К.И. Скрябина, Москва \\ lelemakarov@mail.ru \\ Остапенко Владимир Алексеевич \\ Д.б.н., профессор, Московская государственная \\ академия ветеринарной медицины и биотехнологии \\ имени им. К. И. Скрябина, Москва \\ v-ostapenko@list.ru
}

Аннотация. Антропогенная трансформация среды, в том числе и городских парков оказывает существенное влияние практически на все группы позвоночных животных, В том числе и на птиц. В работе проведен анализ влияния антропогенного загрязнения на разнообразие птиц лесопарков на примере города Москва. Выявлены зависимости снижения видового разнообразия птиц при высоком уровне трансформированности биоценоза.

Ключевые слова: видовое разнообразие, птицы, шумовое загрязнение, световое загрязнение, трансформированные биоценозы, маршрутный учет.

модельных участках города и лесопарков позволяет оценить общее экологическое состояние урбанизированной среды в зависимости от степени антропогенного воздействия.

\section{Цель работы}

Провести анализ влияния антропогенного загрязнения на разнообразие птиц городских парков на примере города Москва.

Процесс проникновения птиц из естественных ландшафтов в городской и приспособление их к обитанию в нем в последнее время стали называть процессом урбанизации птиц. Этот термин «урбанизация» близок к термину «синантропизация» и означает по существу синантропизацию в условиях города, синантропизация и урбанизация - это процессы одного порядка, где синантропизация есть общее понятие, а урбанизация частное.

Город - это искусственная экосистема, в которой преобладает гетеротрофное звено пищевой цепи и изза своей неустойчивости нуждается в постоянном поддержании ее человеком, очистке атмосферного воздуха и водоемов, высадке зеленых насаждений, а также утилизации и переработки отходов [7]. 
Городскую биоту формируют не только растения и животные, но и в большей степени деятельность человека. Поэтому видовой состав фауны городов зависит не только от природных, но и от антропогенных факторов.

Фауна города включает в себя: а) местные виды, изначально обитающие в данной местности (архефиты); б) вселившихся в новое (неофиты) и новейшее (адвентивные виды) время [1].

В настоящее время одной из актуальных задач является изучение и сохранение биологического разнообразия растений и животных, в том числе и обитающих в городе [2].

Москва - самый крупный город страны, настоящий мегаполис, занимающий только в пределах Московской кольцевой автодороги площадь около 887 км². Очевидно, что птицы, обитающие на территории города, оказываются в специфических условиях, что и делает их привлекательным объектом разнообразных исследований — от фаунистических до аут- и синэкологических [8].

Основу населения городских птиц составляют в первую очередь настоящие синантропы - виды, источники пищи и места гнездования которых зависят от человека. Не менее 30 последних лет наиболее многочисленными синантропными видами Москвы остаются кряква, сизый голубь и домовый воробей. С очень высокой плотностью, заведомо превышающей этот показатель за пределами мегаполиса, отмечаются серая ворона и черный стриж. Довольно многочисленны обыкновенный скворец, большая синица и белая трясогузка.

В начале XXI века в Москве в границах МКАД отмечено 245 видов птиц, из них 125 гнездящихся. Это немногим меньше числа видов птиц, которые за тот же период удалось зарегистрировать на территории Московской области (294 вида). Для сравнения: в Лондоне - 130 гнездящихся видов, в Санкт-Петербурге их 166, в Воронеже - 128, в Калининграде - 116.

Москва является достаточно зеленым городом, с большим количеством скверов, лесопарков, городских лесов и видовой состав птиц

сходен с подмосковным, однако имеются отличия. Основными видами города являются представители отряда воробьиных, самые многочисленные из которых это зяблик (плотность поющих самцов может достигать 130 особей / км²), большая синица и лазоревка, пеночка-трещотка (плотность поющих самцов до 50 ос./км²), зарянка, мухоловка-пеструшка, славка-черноголовка, пеночка-весничка и певчий дрозд. Относительно вели- ка в Москве численность соловья, садовой камышевки, садовой славки, чечевицы, реже встречаются сорокопут-жулан, ястребиная славка, славка-мельничек, обыкновенная овсянка. Но настоящее время наблюдается сокращение численности многих видов городских птиц и изменение их видового состава [4].

\section{Материалы и метолы}

Исследования проводились раз в неделю с 10 мая по 10 июня 2019 года. Это связано с особенностью миграции птиц, так как исследуемые птицы прилетают в конце апреля - начале мая. Пункты учета посещались раз в неделю, в утреннее и вечернее время. Уровень шума замерялся в утреннее время, когда уровень загруженности автотранспортом достаточно высок. А уровень светового загрязнения измерялся в вечернее время, когда включалась искусственная иллюминация.

Шум измерялся с помощью прибора “Шумомер PCE322 A". РCE-322A - это портативный, профессиональный измеритель уровня звука или децибелметр со встроенными функциями регистрации или записи данных. Рабочий диапазон от З0дБ до 130 дБ.

Измерения шумового загрязнения проводились утром в 9-ти точках лесопарка (точки указаны ниже). На данном приборе в течение 30 секунд измерялся максимальный уровень шума (в децибелах), затем в течение 30 секунд измерялся минимальный уровень шума (в децибелах), затем в программе Excel проводилась обработка результатов.

Также был измерен уровень светового загрязнения, так как это один из антропогенных факторов, негативно влияющих на птиц. Ежегодный рост светового загрязнения в разных странах Европы составляет от 6\% до 12\%.

Замеры уровня светового загрязнения проводились в вечернее время с помощью профессионального прибора Smart Sensor AS813. Цифровой люксметр AS813 - специализированный измерительный прибор, созданный для определения уровня освещенности в диапазоне значений от 1 до 200000 lux. На данном приборе в течение 30 секунд измерялся максимальный уровень освещенности (в люксах), затем в течение 30 секунд измерялся минимальный уровень освещенности (в люкcax).

Прибор выводит на экран максимальные, либо минимальные значения шума. Обработка результатов проводилась в программе Excel.

Для определения количества птиц был использован маршрутный метод учета, который проводился в лесопар- 
Таблица 1. Результаты измерения уровня шума и света в различных точках лесопарка Кузьминки-Люблино

\begin{tabular}{|l|l|l|} 
Точки & Уровень шума, дБ & Уровень света, лк \\
\hline 1 & $55,50 \pm 7,03$ & $69,2 \pm 2,5$ \\
\hline 2 & $46,61 \pm 4,85$ & $7,1 \pm 1,3$ \\
\hline 3 & $46,86 \pm 4,50$ & $95 \pm 2,1$ \\
\hline 4 & $48,03 \pm 5,80$ & $1,5 \pm 0,5$ \\
\hline 5 & $48,60 \pm 2,88$ & $42,8 \pm 2,1$ \\
\hline 6 & $49,28 \pm 1,93$ & $33,5 \pm 2,8$ \\
\hline 7 & $42,01 \pm 1,89$ & $\sim 0$ \\
\hline 8 & $49,03 \pm 6,40$ & $\sim 0$ \\
\hline 9 & $51,02 \pm 3,31$ & $82,2 \pm 2,4$ \\
\hline
\end{tabular}

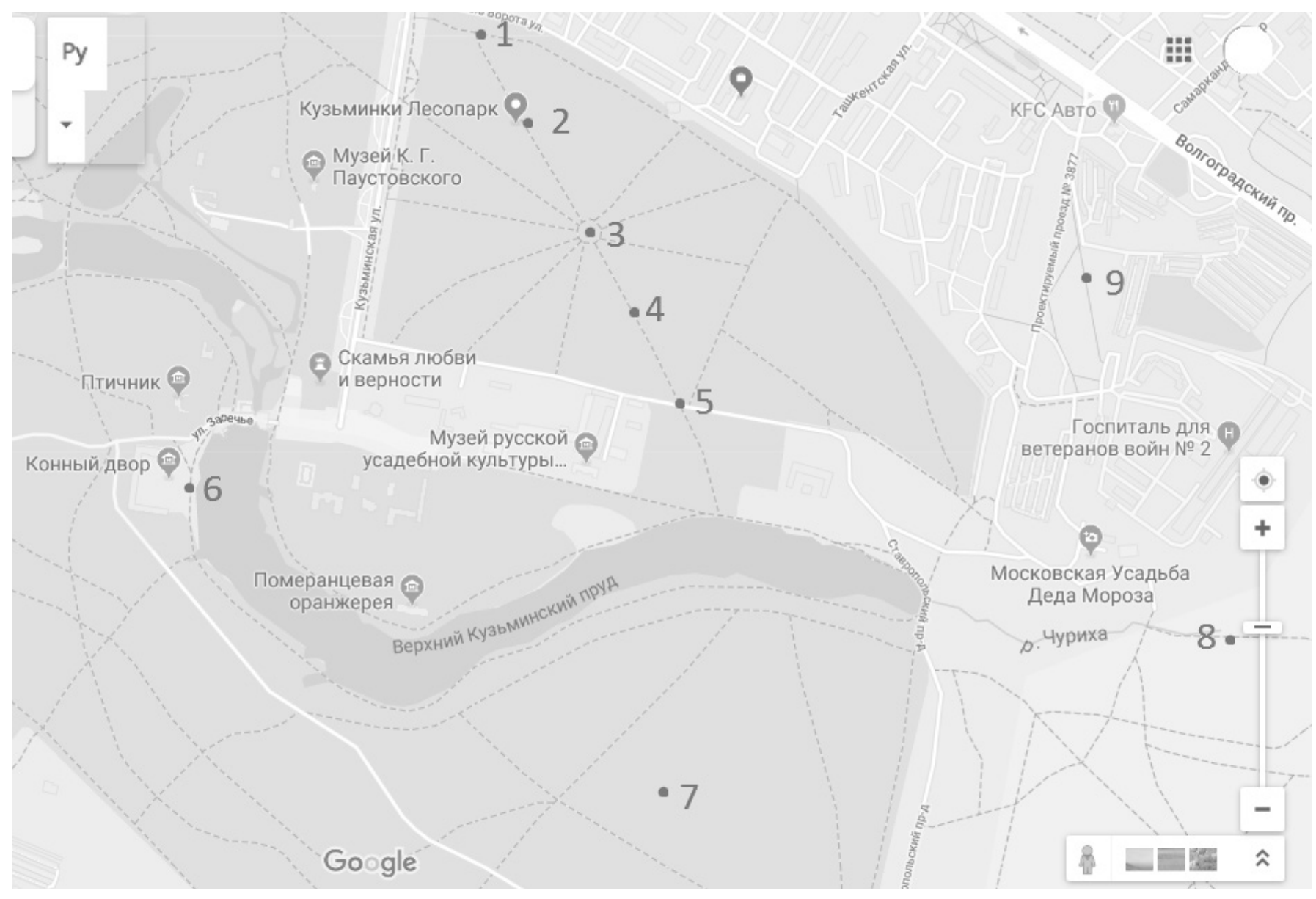

Рис. 1. Карта-схема лесопарка Кузьминки-Люблино с отмеченными точками

ке Кузьминки-Люблино. Птицы регистрировались визуально и на слух, иногда - с помощью бинокля. При этом отмечалось, была ли птица в состоянии пролёта над маршрутом (миграции внутри города или за его пределами) или находилась в пределах биотопа сравнительно постоянно.

При визуальном подсчете птиц в кронах следует учитывать, что в густом лесу одновременно можно ви- деть не более 10-15\% птиц, кормящихся в кронах. Стоит отметить, что большое значение имеет именно общий звуковой фон, производимый птицами. Расстояние до встречаемых на учете птиц определяется в момент обнаружения, т.е. в тот момент, когда птица впервые увидена или услышана. Для целей данной работы выделены четыре группы «дальностей обнаружения»- от 0 до 25 метров («близко»), от 25 до 100 метров («недалеко»), 


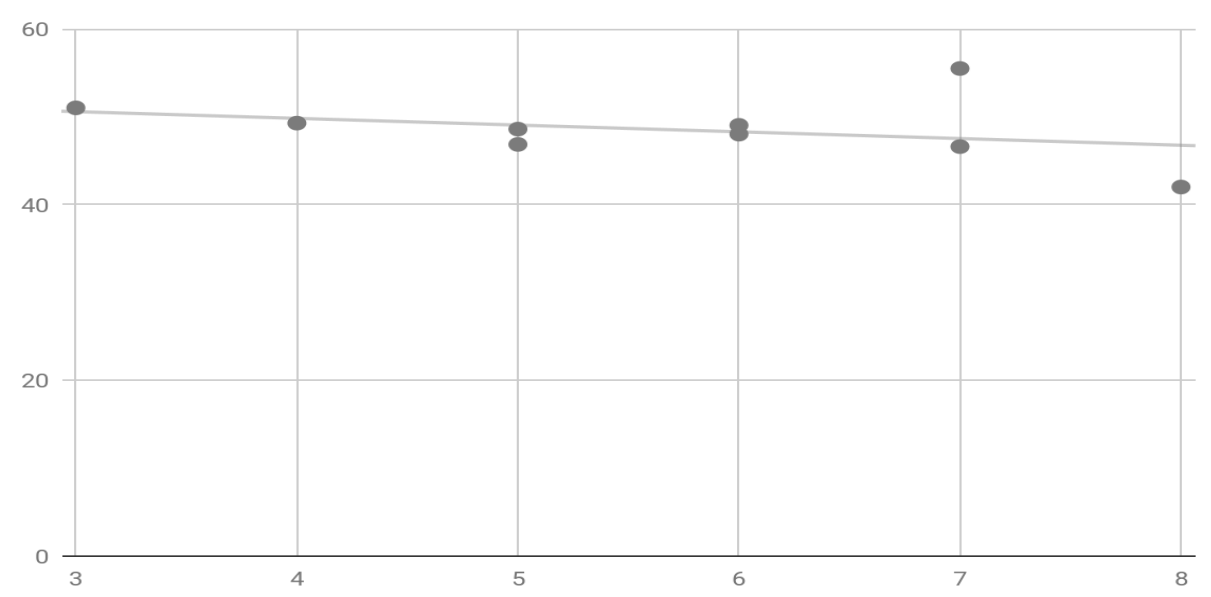

Рис. 2. Влияние шума на количество птиц

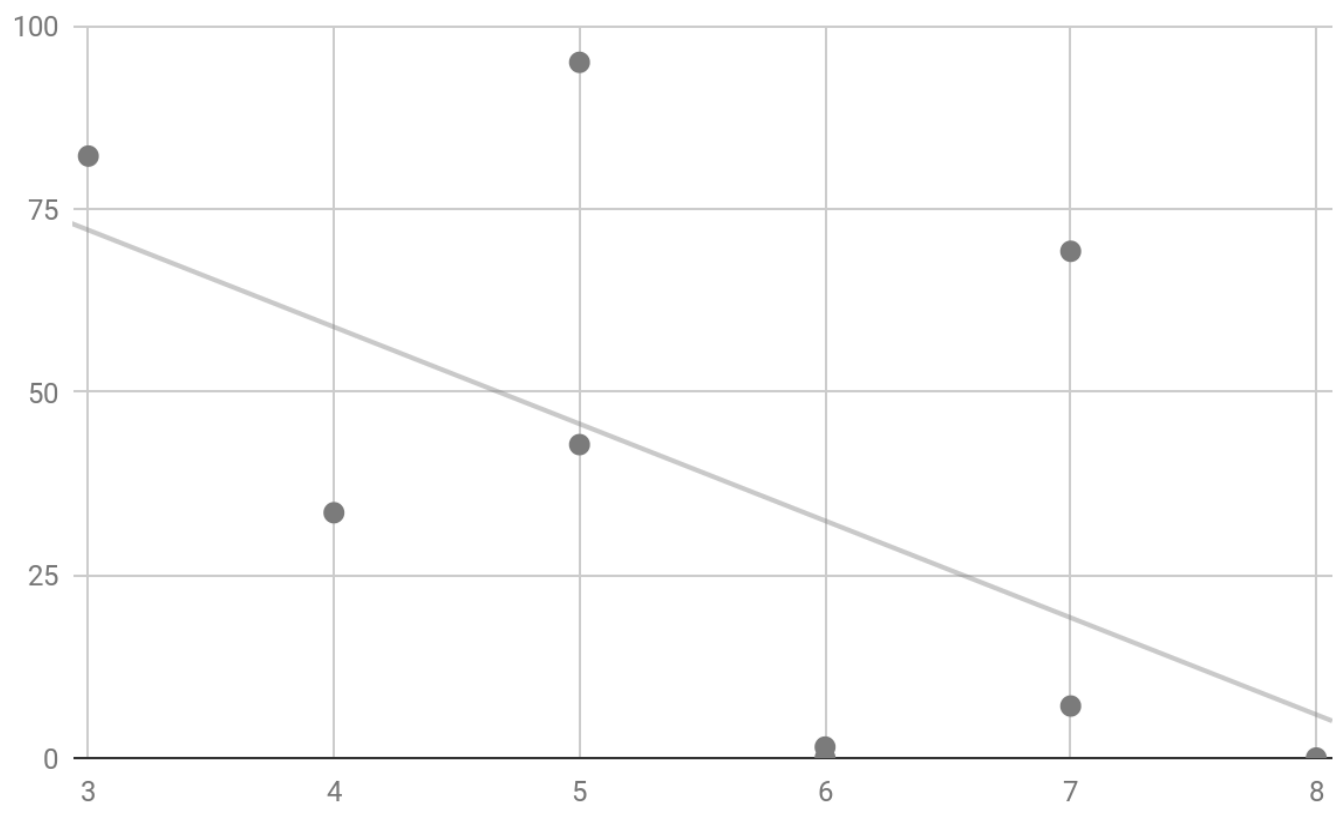

Рис. 3. Влияние света на количество птиц

от 100 до 300 метров («далеко»), и от 300 метров до километра («очень далеко»). (Предполагается, что далее 1 км определить видовую принадлежность птицы затруднительно и не нужно [6].

Все учеты и измерения проводились в 9-ти точках лесопарка (рис. 1)

Была взята карта-схема Лесопарка и отобраны точки с предполагаемым высоким, средним и низким уровнем светового и шумового загрязнения.
Средние значения шумового и светового загрязнения для каждой точки занесены в таблицу 1.

Из таблицы видно, что уровень шумового загрязнения наиболее интенсивный в точках 1, 6, 8 и 9 и составляет от 49,03 дБ до 55,50 дБ. Самый низкий уровень составляет 42,01 дБ в точке 7, где не имелось антропогенных объектов, высокая лесистость, сохранился естественный травяной покров, незначительное количество людей. Средние показатели по шумовому загрязнению наблюдались в точках 2, 3, 4, 5 от до 46,61 дБ 
Таблица 2. Виды птиц, встреченные по маршруту лесопарка Кузьминки-Люблино

\begin{tabular}{|c|c|c|}
\hline Точки № & Виды встреченных птиц & $\begin{array}{l}\text { Кол-во видов/общее } \\
\text { количество встреченных } \\
\text { птиц, голов }\end{array}$ \\
\hline 1 & $\begin{array}{l}\text { дрозд певчий (Turdus philomelos) - } 1 \\
\text { зяблик (Fingilla coelebs)-2 } \\
\text { мухоловка-пеструшка (Ficedula hypoleuca) -2 } \\
\text { синица большая (Parus major) - } 1 \\
\text { трясогузка белая (Motacilla alba) - } 1\end{array}$ & $5 / 7$ \\
\hline 2 & $\begin{array}{l}\text { дрозд певчий (Turdus philomelos) - } 1 \\
\text { дрозд черный (Turdus merula)-1 } \\
\text { зяблик (Fingilla coelebs)-2 } \\
\text { скворец обыкновенный (Sturnus vulgaris) -1 } \\
\text { соловей восточный (Luscinia luscinia) - } 1 \\
\text { трясогузка белая (Motacilla alba) -1 }\end{array}$ & $6 / 7$ \\
\hline 3 & $\begin{array}{l}\text { дрозд черный (Turdus merula) - } 1 \\
\text { мухоловка-пеструшка (Ficedula hypoleuca) }-2 \\
\text { синица большая (Parus major) }-2 \\
\end{array}$ & $3 / 5$ \\
\hline 4 & $\begin{array}{l}\text { дрозд певчий (Turdus philomelos) - } 1 \\
\text { дрозд-рябинник (Turdus pilaris)-2 } \\
\text { дрозд черный (Turdus merula)-1 } \\
\text { зяблик (Fingilla coelebs)-1 } \\
\text { скворец обыкновенный (Sturnus vulgaris) - } 1 \\
\end{array}$ & $5 / 6$ \\
\hline 5 & $\begin{array}{l}\text { зяблик (Fingilla coelebs) -3 } \\
\text { синица большая (Parus major) -2 }\end{array}$ & $2 / 5$ \\
\hline 6 & $\begin{array}{l}\text { дрозд певчий (Turdus philomelos) - } 1 \\
\text { зяблик (Fingilla coelebs) - } 2 \\
\text { мухоловка-пеструшка (Ficedula hypoleuca) - } 1\end{array}$ & $3 / 4$ \\
\hline 7 & $\begin{array}{l}\text { дрозд певчий (Turdus philomelos) - } 1 \\
\text { дрозд-рябинник (Turdus pilaris) - } 1 \\
\text { дятел средний пестрый(Dendrocopos medius) -1 } \\
\text { зяблик (Fingilla coelebs) - } 1 \\
\text { мухоловка-пеструшка (Ficedula hypoleuca) - } 1 \\
\text { синица большая (Parus major) - } 2 \\
\text { скворец обыкновенный (Sturnus vulgaris) -1 }\end{array}$ & $7 / 8$ \\
\hline 8 & $\begin{array}{l}\text { дрозд черный (Turdus merula)-2 } \\
\text { зяблик (Fingilla coelebs)-2 } \\
\text { синица большая (Parus major) - } 1 \\
\text { славка черноголовая (Sylvia articapilla) - } 1\end{array}$ & $4 / 6$ \\
\hline 9 & $\begin{array}{l}\text { дрозд певчий (Turdus philomelos) - } 1 \\
\text { зяблик (Fingilla coelebs) -2 }\end{array}$ & $2 / 3$ \\
\hline
\end{tabular}

до 48,60 дБ. В этих точках встречалось малое количество людей.

Самый высокий уровень светового загрязнения в точках 1, 3, 9 составляет от 69,2 лк до 95 лк, в этих точках расположены фонари, освещающие местность. Самый низкий уровень светового загрязнения 0 лк в точках 7 и 8. Это глубь парка, где нет протоптанных тропинок и фонарей и место за Усадьбой Деда Мороза, где не имеется фонарей. Средний уровень в точках 2, 4, 5, 6 .
Рассмотрим график, наглядно оказывающий зависимость количество птиц от шумового загрязнения (рис. 2).

Линия тренда на графике показывает зависимость количества птиц от шумового загрязнения. Как видно по графику, шумовое загрязнение мало влияет на птиц. Видимо, они адаптировались к постоянному шуму, отличному от естественных условий. Самое меньшее количество птиц в точке 9, где проходит линия электропередач, от которых исходит постоянный шум в виде треска, 
Таблица 3. Список обнаруженных видов птиц и их количество

\begin{tabular}{|l|l|l|}
\hline$№$ & Вид & Общее кол-во \\
\hline 1 & Дрозд певчий (Turdus philomelos) & 6 \\
\hline 2 & Дрозд-рябинник (Turdus pilaris) & 3 \\
\hline 3 & Дрозд черный (Turdus merula) & 5 \\
\hline 4 & Дятел средний пестрый (Dendrocopos medius) & 1 \\
\hline 5 & Зяблик (Fingilla coelebs) & 15 \\
\hline 6 & Мухоловка-пеструшка (Ficedula hypoleuca) & 6 \\
\hline 7 & Синица большая (Parus major) & 7 \\
\hline 8 & Скворец обыкновенный (Sturnus vulgaris) & 2 \\
\hline 9 & Славка черноголовая (Sylvia articapilla) & 1 \\
\hline 10 & Соловей восточный (Luscinia luscinia) & 1 \\
\hline 11 & Трясогузка белая (Motacilla alba) & 2 \\
\hline
\end{tabular}

Таблица 4. Негативные факторы, влияющие на жизнь птиц

\begin{tabular}{|c|c|c|c|c|c|c|}
\hline Точки № & $\begin{array}{l}\text { Наличие } \\
\text { поблизости } \\
\text { больших } \\
\text { автодорог }\end{array}$ & $\begin{array}{l}\text { Высокая } \\
\text { посещаемость } \\
\text { людьми }\end{array}$ & $\begin{array}{l}\text { Отсутствие } \\
\text { удобных мест для } \\
\text { гнездования }\end{array}$ & $\begin{array}{l}\text { Изменение } \\
\text { ландшафта }\end{array}$ & $\begin{array}{l}\text { Шумовое } \\
\text { загрязнение }\end{array}$ & $\begin{array}{l}\text { Световое } \\
\text { загрязнение }\end{array}$ \\
\hline 1 & ++ & + & + & + & ++ & + \\
\hline 2 & - & - & - & - & + & - \\
\hline 3 & - & + & + & ++ & + & ++ \\
\hline 4 & - & - & - & - & + & - \\
\hline 5 & + & + & + & + & + & + \\
\hline 6 & - & ++ & + & + & ++ & + \\
\hline 7 & - & - & - & - & + & - \\
\hline 8 & - & + & - & + & ++ & - \\
\hline 9 & ++ & + & + & ++ & ++ & ++ \\
\hline
\end{tabular}

\section{Количество птиц в лесопарке}

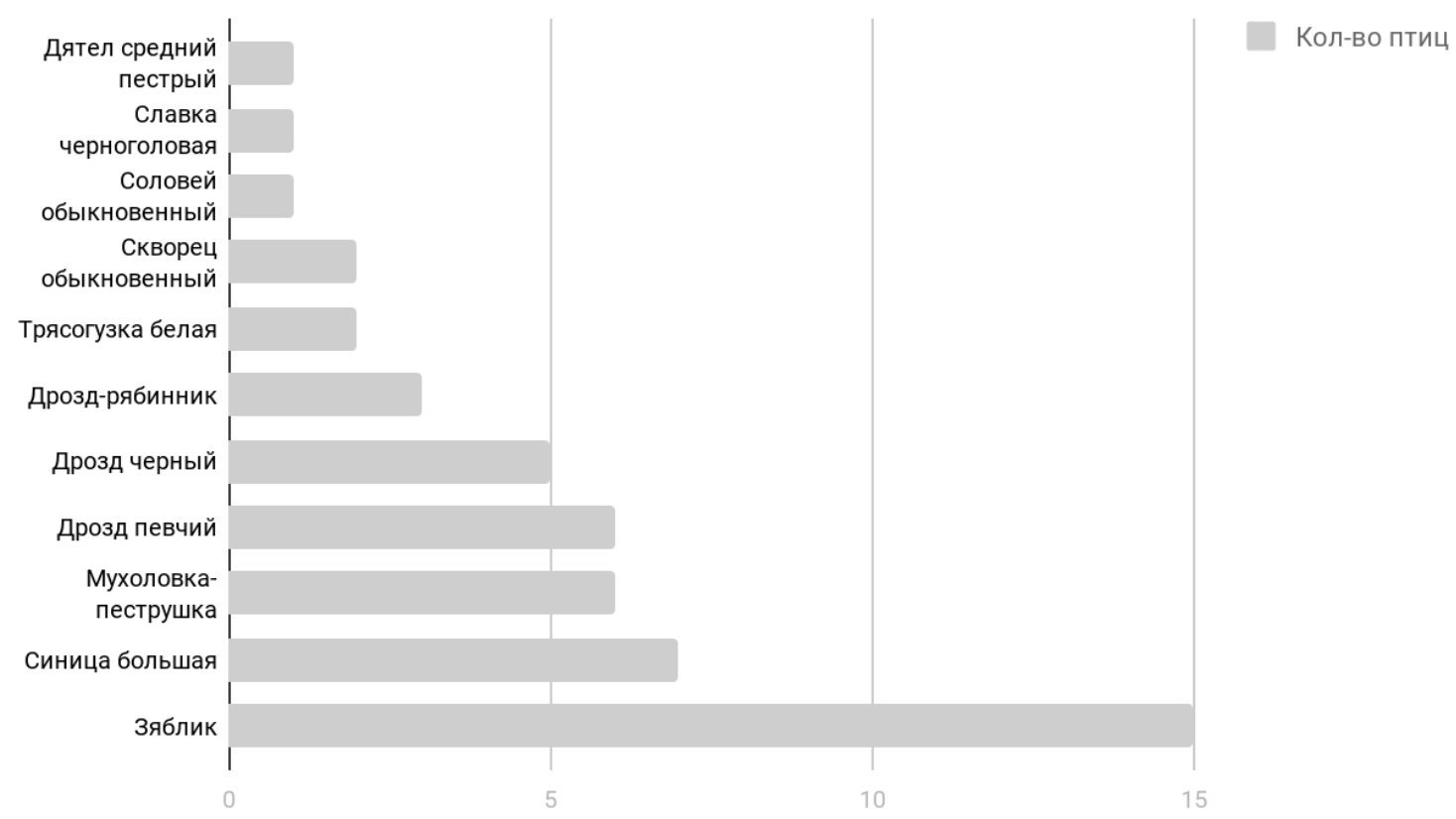

Рис. 4. Видовое разнообразие и показатели доминирования птиц лесопарка 
уровень шума в этой точке составляет 51,02 дБ. И в точке 3 также было обнаружено малое количество птиц, уровень шумового загрязнения там составляет 49,28 дБ. В этой точке находятся много кафе, часто играет музыка, отмечено большое скопление людей. Самое большое количество птиц в точке 7 (8 особей), которая находится в глубине лесопарка Кузьминки-Люблино, где шум составляет 42,01 дБ - самый низкий уровень шума из всех точек. На основании полученных данных можно говорить о том, что уровень шума не влияет на разнообразие и количество птиц, скорее всего может оказывать влияние характер шумового загрязнения (лай собак, голоса людей, громкая музыка).

Также был построен график зависимости количества птиц от светового загрязнения (рис. 3).

Как видно на рисунке 3 зависимость количества птиц от уровня света. Чем больший уровень освещенности, тем меньшее число птиц было зафиксировано. Бывают исключения, как, например, в точке 1, где уровень светового загрязнения составляет 69,2 лк, а количество птиц -7.

В точке 7, где уровень освещенности составляет 0 лк, присутствует большее количество птиц (8 особей). На этой точке имеется естественный растительный покров, дикорастущие травы и кустарники, а фонарей там нет. Также нет фонарей и в точке 8, но птиц там меньше, вероятно, из-за высокого уровня шумового загрязнения (49,03 дБ). Меньше всего птиц обнаружено в точке 9 (3 особи), где проходит линия электропередач и имеются фонари вдоль дороги. И в точке 6 (4 особи), которая хорошо освещена. Также там имеется дополнительное освещение от различных кафе.

Проходя по данному маршруту, фиксировались увиденные и услышанные птицы. Получен данные занесены в таблицу 2.

Общее количество видов, зафиксированных в период исследования было занесено в таблицу 3, на основании таблицы была построена диаграмма (рис. 4).
Всего здесь было встречено 11 видов. Нами выявлен ряд птиц, на которых не влияет антропогенное загрязнение и трансформированность экосистемы. Это зяблик, большая синица, мухоловка-пеструшка и певчий дрозд. Эти птицы стали синантропными, они приспособились жить рядом с человеком и встречаются широко. Восточный соловей, средний пестрый дятел и славка-черноголовка встречаются достаточно редко в связи с приуроченностью к определенным видам гнездования, которые в парке нарушены: вырубаются деревья, кустарники, подсаживаются декоративные травы.

Из таблицы 4 видно, что в точке 7 меньше всего негативных факторов, влияющих на жизнь птиц. Уровни шумового и светового загрязнения там тоже низкие. В точках 1 и 9 больше всего преобразований, рядом находятся автодороги, трансформирован биоценоз и достаточно высокие уровни шума и освещенности. В точке 5 также достаточно много негативных факторов, но стоит отметить, что уровень светового загрязнения там средний.

\section{Зак^ючение}

В результате проделанной работы нами было выявлено ряд изменений в лесопарке Кузьминки-Люблино, которые проявлялись в антропогенном загрязнении: шумовом и световом, а также трансформации биоценоза в виде вырубки деревьев, сведения естественной растительности и подсева декоративных трав, установлении лавочек и пр.

Из проведенных исследований видно, что шум не влияет на количество видового разнообразия птиц. Найдена зависимость количества и разнообразия птиц от уровня светового загрязнения.

Было обнаружено, что основной причиной снижения видового разнообразия является уровень трансформированности биоценоза.

Для сохранения биологического разнообразия необходимо в городских лесопарках сохранять естественные условия, которые будут способствовать сохранению биологического разнообразия.

\section{ЛИТЕРАТУРА}

1. Алинзер А.С Качество городской среды как фактор интенсификации прогресса // Проблемы качества городской среды. - М.: Экология, 2010.— C. 33-35.

2. Дорофеев С. А. Учет численности зимующих и гнездящихся птиц города. Методические рекомендации для студентов биологических специальностей.Витебск: Издательство ВГУ им. П. М. Машерова, 2002.- 20 с.

3. Иванова А. Н. Влияние параметров придорожных лесных полос на снижение шума вблизи автомобильных дорог (на примере саратовского правобережья): дисс. канд. биол. наук. Саратов, 2014. С. 118. URL: http://www.sgu.ru/sites/default/files/dissertation/2014/09/23/ivanovaas_diss.p

4. Ильичёв В.Д., Фомин Е. В. Орнитофауна и изменение среды (на примере Южно-Уральского региона). М.: Наука, 1988, 247 с.

5. Орешкина, Т. А. Социальная экология: учеб. пособие / Т. А. Орешкина, В. А. Ко- няшкин, Е. А. Купрессова; М-во науки и высш. образования Рос. Федерации, Урал. федер. ун-т.—Екатеринбург: Изд-во Урал. ун-та, 2018. — 128 с. 
6. Равкин, Ю.С. К методике учета птиц в лесных ландшафтах /Ю.С. Равкин // Природа очагов клещевого энцефалита на Алтае.— Новосибирск, 1967 C. 66-75.

7. Рыбкина, И. Д. Экосистема города Бийска: проблемы и особенности функционирования, оценка качества среды жизни населения/ И. Д. Рыбкина // Известия Бийского отделения Русского географического общества.— 2012.— № 8.— С. 123-127.

8. Храбрый В.М. (ред.) Птицы городов России.— М.: КМК, 2012.— 514 с.

○ Макарова Елена Александровна ( lelemakarov@mail.ru ),Остапенко Владимир Алексеевич ( v-ostapenko@list.ru ). Журнал «Современная наука: актуальные проблемы теории и практики»

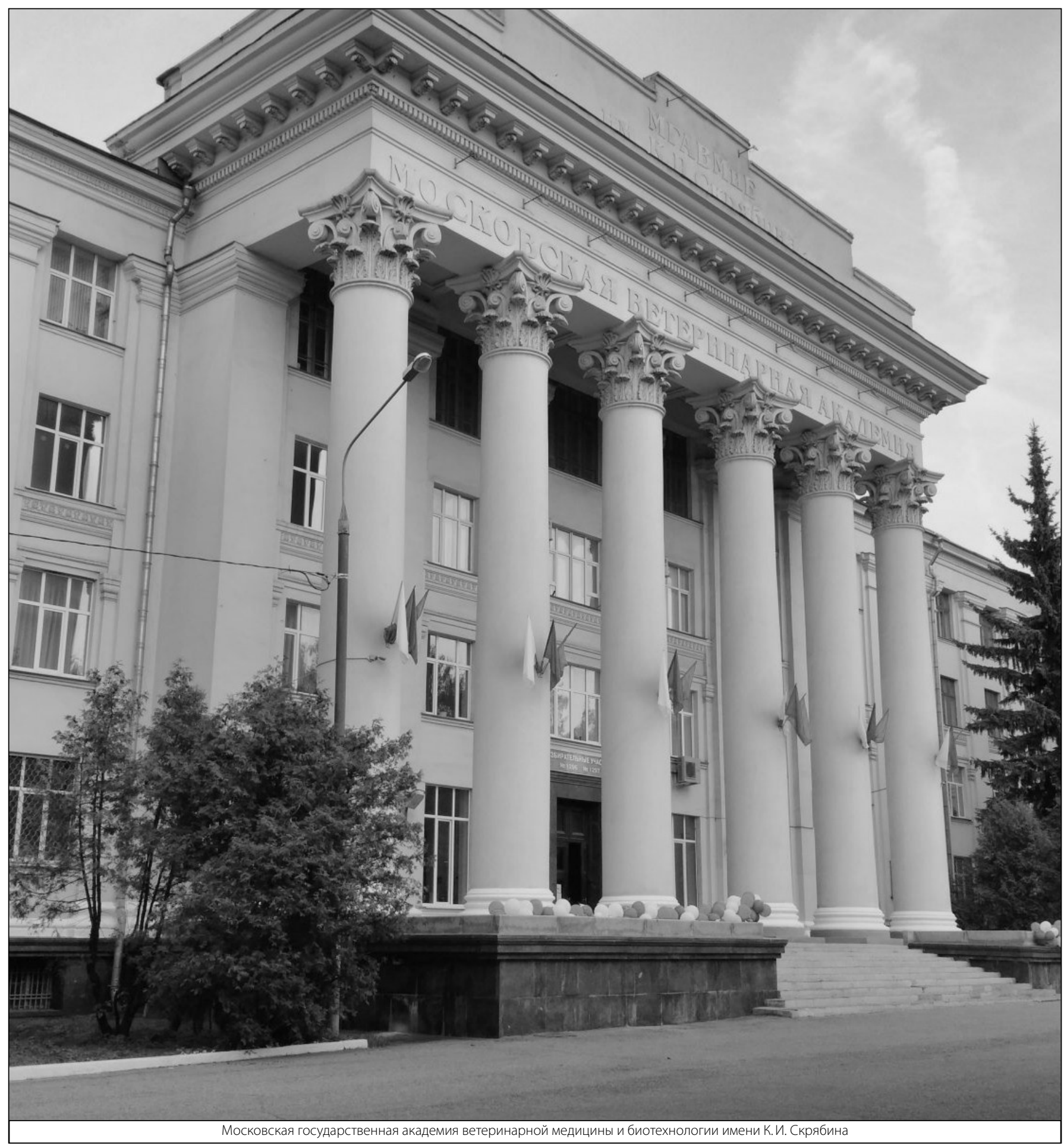

